\title{
ENHANCING STUDENT LEARNING THROUGH ProACTIVE FEEDBACK BASEd AdAPTIVE TEACHING FOR ENGINEERING COURSES
}

\author{
Danda B. Rawat and Chandra Bajracharya
}

Dept. of Electrical Engineering, Georgia Southern University, Statesboro, GA,USA

\begin{abstract}
This paper presents a proactive anonymous feedback based adaptive teaching for enhancing student learning for engineering courses. In conventional university teaching, typically, students come to the class and instructors lecture the material, assign home assignments, take exams, etc. After grading assignments or exams, the instructor provides feedback to students. Most of the time, students are reluctant to ask questions or ask instructor to revisit the topic which was already covered. However, there is no immediate anonymous feedback mechanism for each topic or class to notify the instructor about topics which are not clear to students. There are advantages that enhance students' learning experience by using a proactive anonymous feedback approach in teaching, learning and assessment. In this paper, we present the immediate impacts of proactive anonymous feedback based adaptive teaching on student learning and assessment. Furthermore, anonymous online based feedback mechanism provides faster feedback than conventional mechanism (where students wait until the first exam or so). Immediate feedback for each topic discussed in the class streamlines the process of reporting and the provision of active studying. The results show that students get better grade and instructors get better student evaluation score since the anonymous feedback provides a mechanism for students to ask questions anonymously and the instructors get an opportunity to answer the questions or concerns in a timely manner. We implemented the proactive anonymous feedback approach in many courses in different semesters and observed similar results. However, as an example, we present one course and instructor to illustrate the effectiveness of the proposed approach.
\end{abstract}

\section{KEYWORDS}

Technology-enhanced learning, Adaptive teaching, student feedback based teaching, enhancing learning outcomes.

\section{INTRODUCTION}

Most university students learn through attending lectures, completing homework assignments and quizzes, participating in face-to-face group tutorials, and attending in exams as part of full-time campus-based programs $[1,3,4,5]$. Students get opportunities to interact with their professors or instructors in the classroom as well as during allocated office hours. However, most of the students are reluctant to ask in the class as they might feel that the questions they ask are very basic or advanced $[1,2,4]$. The only way to ask questions either by sending email or meeting professors during office hours. Even in this case, most students are reluctant to ask questions as they have fear of being identified as a weak student. Only option available to students is study by themselves or ask colleagues. In this paper, we present a proactive anonymous feedback mechanism where students use online forms (e.g., Google form) to provide anonymous feedback to their instructors and ask questions about any topics that is not clear to them. This feedback mechanism doesn't collect any private information that identifies the students. Thus, student can 
ask any questions fearlessly. Note that the proposed proactive anonymous feedback mechanism is in addition to regular homework assignment, quizzes, tests, class discussions, term paper assignment, etc. There are many advantages that enhance students' learning experience by using a proactive anonymous feedback approach in teaching, learning and assessment. Furthermore, anonymous online based feedback mechanism provides faster feedback than conventional mechanism (where students wait until the first exam or so). Immediate feedback for each topic discussed in the class streamlines the process of reporting and the provision of active studying for feedback. The results show that students get better grade and instructors get better student evaluation score since the feedback provides a mechanism for student to ask questions anonymously and instructors get a chance to answer the questions or concerns in a timely manner. We implemented the proactive anonymous feedback approach in many courses in different semesters and observed similar results. In this paper, as an example, we present one course and instructor to illustrate the effectiveness of the proposed proactive anonymous feedback approach.

Most recent related works include [6,7,8] where students receive feedback from instructors through corrected assignments (homework, testes, quizzes, exams, etc.). Using these assignments as references, instructor realizes that the students are not at the level that instructed expected. Furthermore, students who are not hesitant to speak out in the class can also provide some feedback so that instructor can identify the problems and adapt his/her teaching style or material to improve teaching and learning for the betterment of the students. It is worth noting that using these approaches, instructors do not receive feedback about their teaching style and materials in a timely manner. Furthermore, these approaches are not proactive and are not capable of providing mechanism of giving anonymous feedback to the instructor from which most students get benefit.

\section{MeTHODOLOGY/ProcesS}

In each class, instructors presented the agenda where announcements are announced first and followed by the review as shown in Figure 1. The review of previous topics is done to connect the previous topics with the topics that are going to be discussed in the class. During this review time, instructor also reviews the topics mention in the anonymous feedback. The instructor also proactively asks the students about anonymous feedback for the topic or any questions that students have (if any). Students are also suggested to study the lecture material (for at least 15 minutes) after each class. This helps students to understand the topics discussed in the class. If something is still not clear yet, students are encourages to write about what is unclear to them and the instructor should consider revisiting in the following class before starting the next topic.

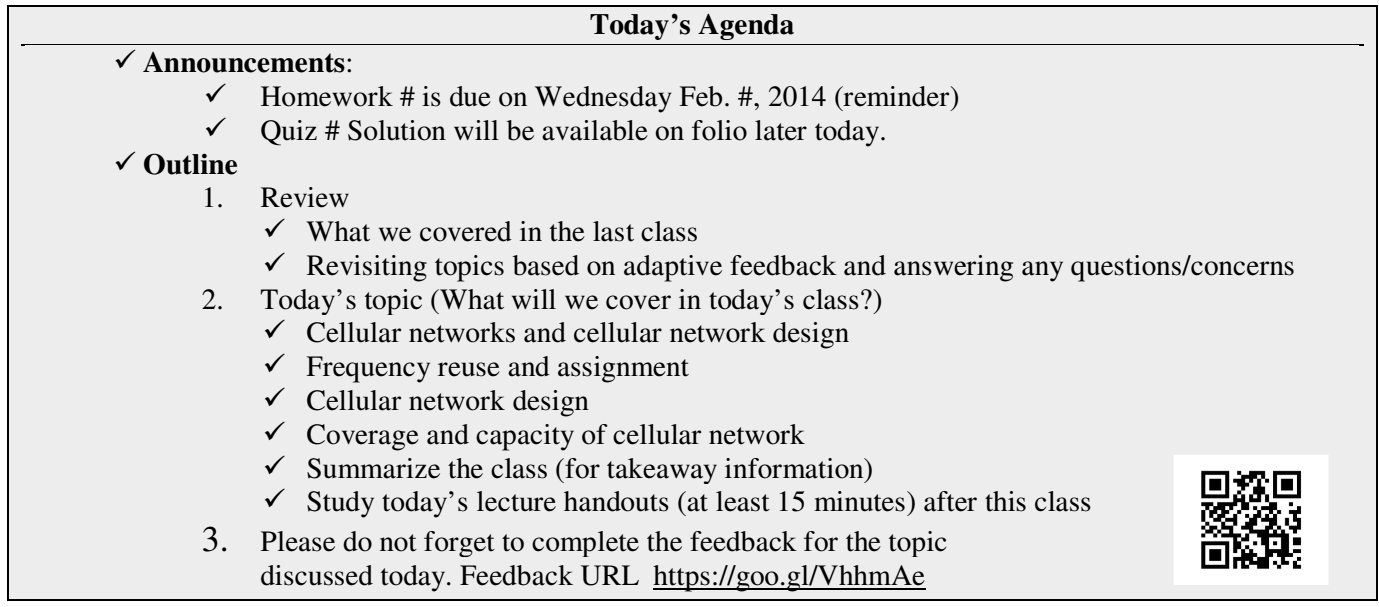

Figure 1. A typical Lecture slide with the agenda for a given class. 


\subsection{Feedback Forms and Process}

This section presents feedback form and process that are used in anonymous feedback process for engineering courses. Figure 2 shown the form for EENG 5532 Wireless Communications course as an example. The process of collecting feedback is anonymous to give students an opportunity to share their thoughts and feelings about the given topic, lecture materials, instructors, etc. without releasing their identity or without any fear.

A typical list of topics covered in wireless communications course at GSU are listed as shown in Figure 2. After finishing each topic, students are encourages to provide feedback about the topic, instruction methods, etc. by choosing the correct item from dropdown box as shown in Figure 2 .

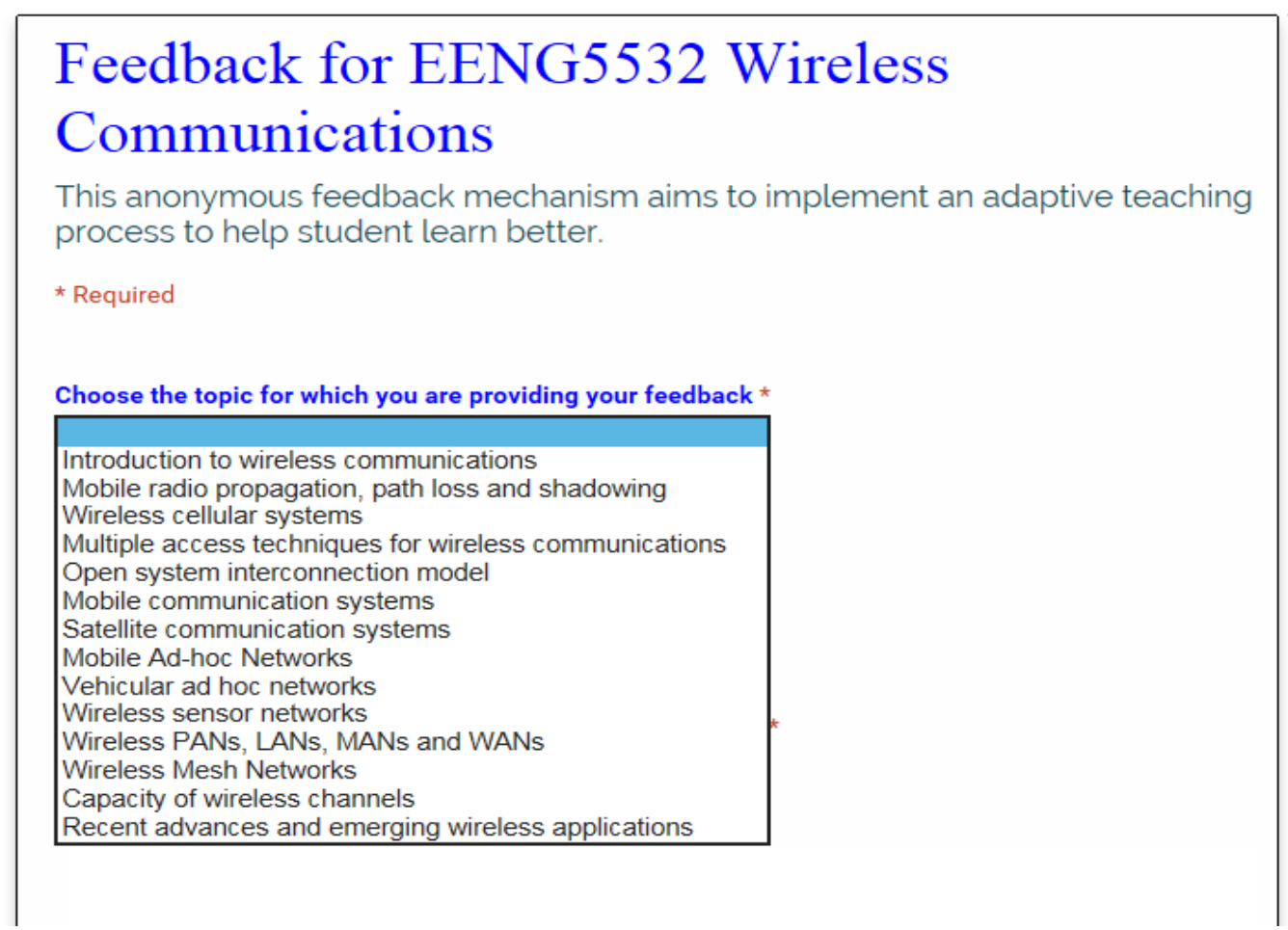

Figure 2. List of topics for the given course listed in dropdown list.

Figure 3 shows the complete list of questions (with additional overall feedback) about the topic covered in wireless communications course. When instructor covered a given topic in the class, students are asked/encourages to participate in this anonymous feedback process within 24 hours. This early feedback allows instructor to read the comments/feedback in a timely manner. Furthermore, if there are some topics unclear to students, instructor gets an opportunity to revisit the topics based on the feedback while reviewing the previous topics in the class. The main goal of this process is to help students to relate the topics and make connection between different topics that were covered in different classes.

Regardless of the feedback from students, instructors revisit the previous topics to make smooth transitions between two topics (topics discussed in the previous class and topics that are going to be discussed). Note that, on top of feedback, instructor assigns home assignment every week, at least a quiz after finishing each topic, term paper for the course, at least three test (including final exam) for the evaluation and assessment. 


\section{Feedback for EENG5532 Wireless Communications}

This anonymous feedback mechanism aims to implement an adaptive teaching process to help student learn better.

* Required

Choose the topic for which you are providing your feedback *

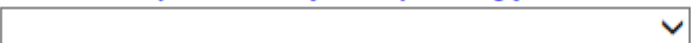

Were the lecture and content interesting? *

$\begin{array}{lllll}1 & 2 & 3 & 4 & 5\end{array}$

Very uninteresting $\bigcirc \bigcirc \bigcirc \bigcirc$ Very interesting

Were lecture and content adequate in terms of the coverage of the subject? *

$\begin{array}{lllll}1 & 2 & 3 & 4 & 5\end{array}$

Poor Coverage $\bigcirc \bigcirc \bigcirc \bigcirc$ Excellent Coverage

Did you understand the lecture and content well? *

$\begin{array}{lllll}1 & 2 & 3 & 4 & 5\end{array}$

Not at all $\bigcirc \bigcirc \bigcirc \bigcirc$ Definitely

Instructor precisely answered the questions *

$\begin{array}{lllll}1 & 2 & 3 & 4 & 5\end{array}$

Not at all $\bigcirc \bigcirc \bigcirc \bigcirc$ Completely and precisely

What is your overall opinion of this course? *

$\begin{array}{lllll}1 & 2 & 3 & 4 & 5\end{array}$

Poor $\bigcirc \bigcirc \bigcirc \bigcirc$ Very good

What specific things did the instructor do that succeeded in helping you learn in this topic? Please be specific: interaction with students, analogy, examples, demonstrations, videos, etc.



Figure 3. Complete form for student to provide feedback to the instructor anonymously (contd.) 


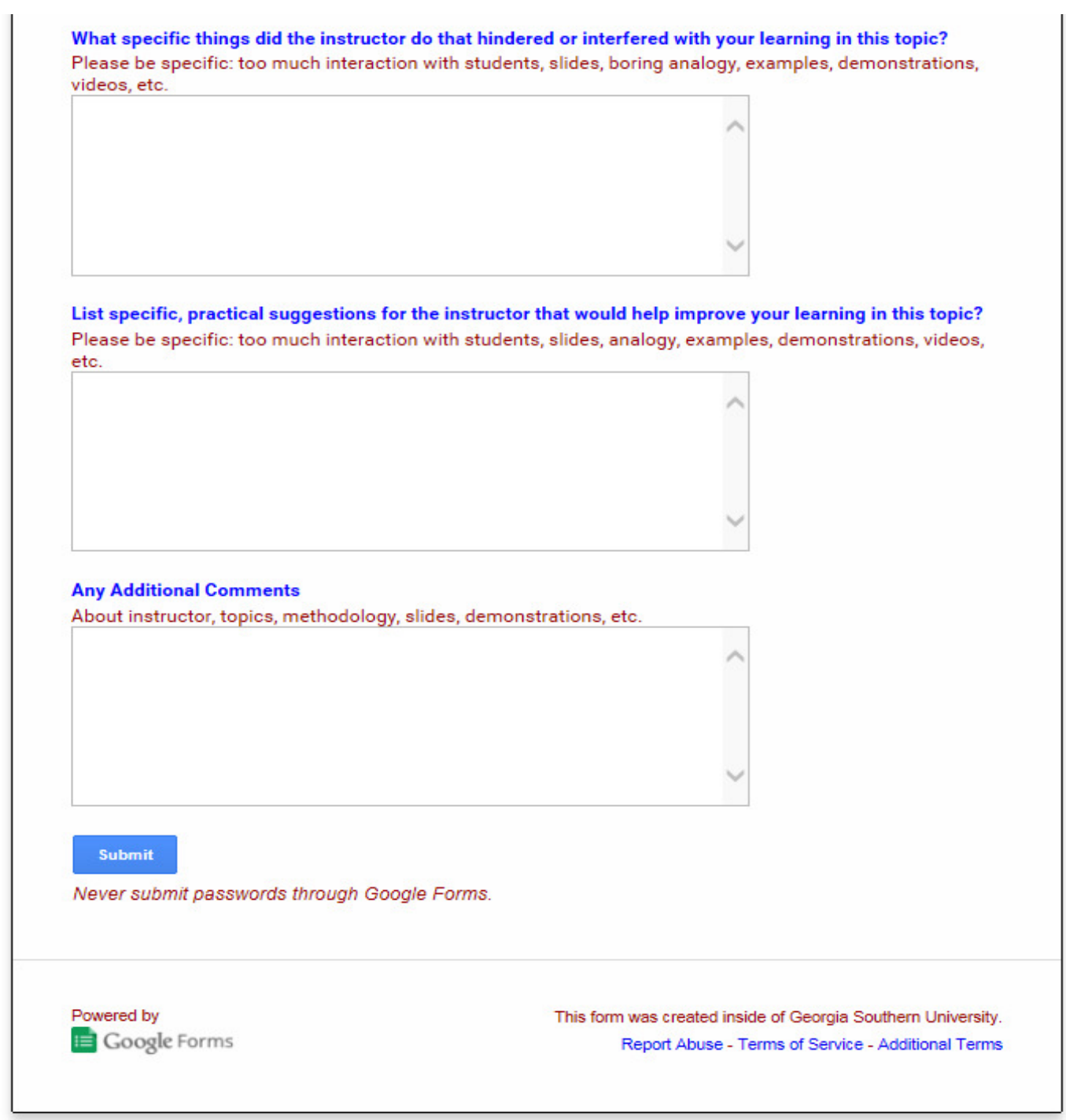

Figure 3. Complete form for student to provide feedback to the instructor anonymously (contd.)

\subsection{Feedback Response for a Given Course}

As mentioned, after covering each topic students were encouraged to participate in the feedback process. The feedback provided by the students was read by the instructor and took adaptive action to close the loop and for better teaching and learning process. In addition to homework and tests, pop-up quizzes were also assigned during class time to assess the effectiveness of teaching and learning. Students were provided their progress in a regular basis.

The Table 1 below shows the number of responses received in spring 2014 and spring 2016 for each topic of the given course. Most of the students were participating with some exception. For example, there were very few providing for the last topic as the topic was discussed in the very last class and student might have thought that there is no time for the instructor to provide the response to students. 
International Journal on Integrating Technology in Education (IJITE) Vol.4,No.3,September 2015

Table 1. Number of responses received for each topic in spring 2014 and 2015 semester.

\begin{tabular}{|c|c|c|c|}
\hline No. & Topic & $\begin{array}{c}\text { No. of } \\
\text { participants in } \\
\text { spring } 2014\end{array}$ & \begin{tabular}{|c|} 
No. of participants \\
in \\
spring 2015
\end{tabular} \\
\hline 1 & Introduction to wireless communications & 10 & 14 \\
\hline 2 & Mobile radio propagation, path loss and shadowing & 9 & 14 \\
\hline 3 & Wireless cellular systems & 10 & 14 \\
\hline 4 & Multiple access techniques for wireless communications & 9 & 14 \\
\hline 5 & Open system interconnection model & 8 & 13 \\
\hline 6 & Mobile communication systems & 10 & 11 \\
\hline 7 & Satellite communication systems & 10 & 12 \\
\hline 8 & Mobile Ad-hoc Networks & 10 & 14 \\
\hline 9 & Vehicular ad hoc networks & 10 & 14 \\
\hline 10 & Wireless sensor networks & 9 & 13 \\
\hline 11 & Wireless PANs, LANs, MANs and WANs & 10 & 12 \\
\hline 12 & Wireless Mesh Networks & 10 & 10 \\
\hline 13 & Capacity of wireless channels & 10 & 8 \\
\hline 14 & Recent advances and emerging wireless applications & 4 & 9 \\
\hline
\end{tabular}

\subsection{Aggregated Comments Received from Students for Different Topics}

The following lists show the comments received from students anonymously using the form in Figure 3 for different questions asked in Figure 3. Note that in addition to questions provided in feedback process, students also got opportunities to ask questions during class and office hours.

\section{What specific things did the instructor do that succeeded in helping you learn in this topic?}

- Animation with different cell size helped me to understand how cellular network planning is done.

- Demonstration and animations during PPT slides.

- Cellular concept was new to me but animation and drawing on the board made me things clear.

- Animation in PowerPoint slides helped me understand the concept.

- CDMA concept through examples.

- Analogy, explanation and animations were good to help me understand.

- History of wireless communications was great.

- Giving overall picture of the field.

- Vehicular communication with animated propagation effect was cool.

- Satellite communication discussion was more than I expected which is good.

- Emerging wireless applications topic was motivational. 


\section{What specific things did the instructor do that hindered or interfered with your learning in this topic?}

- Keep up the good work.

- None

- N/A

- none

- You could have divided PAN, LAN and MAN topics into more sessions.

- Please cover more about PAN and LAN technologies and applications

- Less examples. Plz include more examples for practice

\section{List specific, practical suggestions for the instructor that would help improve your learning} in this topic?

- Nothing.

- NA

- You showed some demos or videos but some hands-on lab activities related to each topics could help me understand better.

- Animation of CDMA signal would help me to see how CDMA cellular systems works.

- Please assign more examples or homework problem in cellular systems.

- In my opinion, wireless mesh network in one lecture is not sufficient. Can you present about more applications of mesh networking in next class?

- More practice problems would be good

\section{Any Additional Comments}

- I like the lecture about how things got changed over the time in wireless communication area. I think wireless will have big impact in all areas in the years to come. My view about wireless communication got changed after the first class. Great motivational class.

- Mapping TDMA, CDMA, and FDMA techniques with service providers such as T-mobile, AT\&T, Verizon, Sprint, etc. was new to me. It was cool

- You know how to make lecture interesting

- My concentration is not communication but I am thinking of changing it.

- None

- Good class.

- Best prof. I ever had. You are motivational teacher which is good.

- You know how to present the topic to make interesting. :)

- Cellular concept to increase overall capacity of the network is cool.

- Great job. Keep it up!

- Excellent job.

- You are the man.

- Can you do more examples for CDMA systems for both transmitter and receiver? 


\subsection{Student Rating Collected Through the Feedback Process}

Figure 4 shows the average score for feedback questions for each topic of the course. Except very few, most of the topics were interesting to all students as average score is 5 out of 5 . The lower rating may be because of the students who missed previous class and felt disconnected in the following class as a result they gave low ratings.

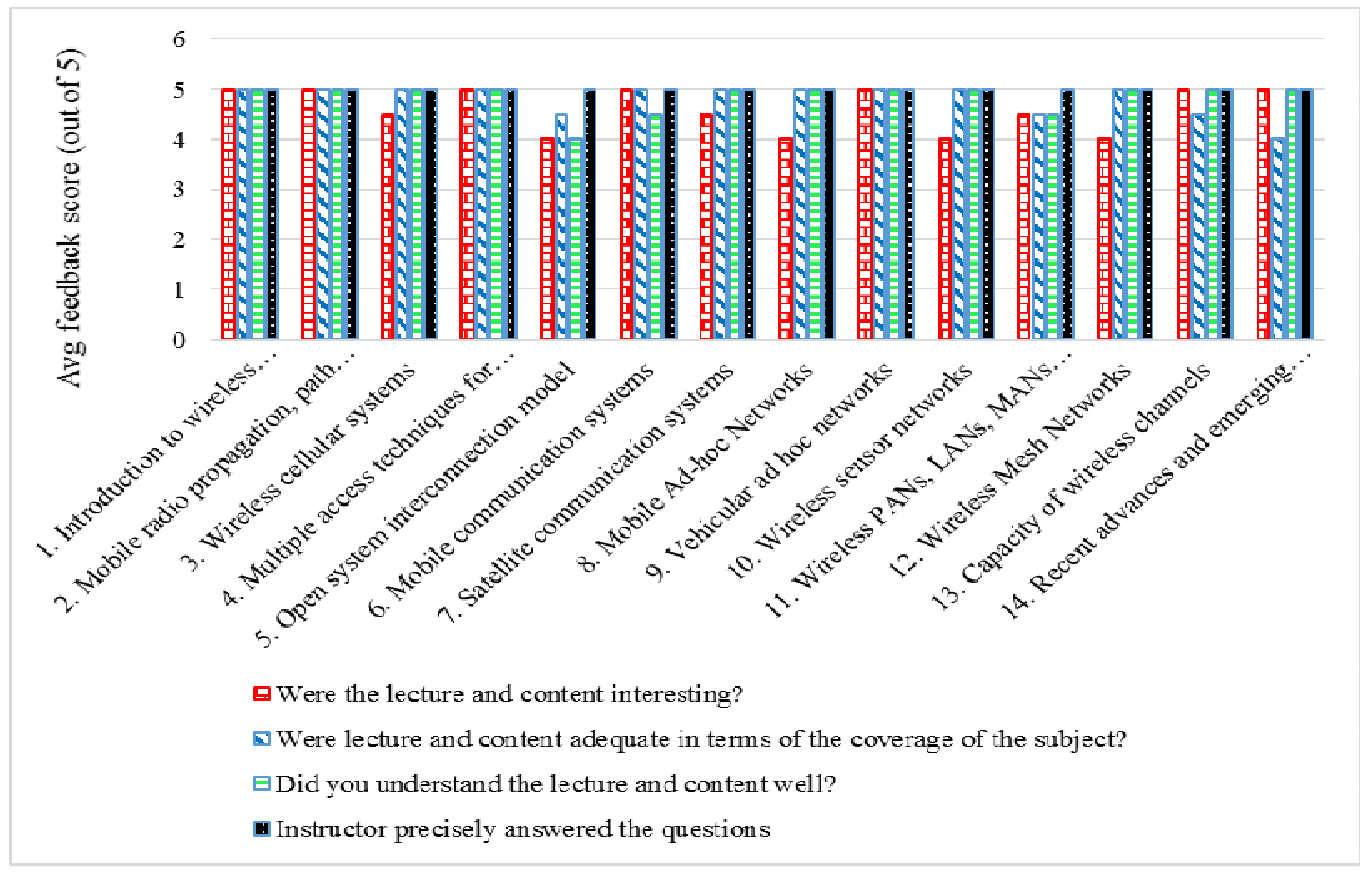

Figure 4. Average score received from students after implementing an adaptive feedback mechanism for a given course based on Figure 3.

\subsection{Impact on Learning Outcomes, Grades and Assessment}

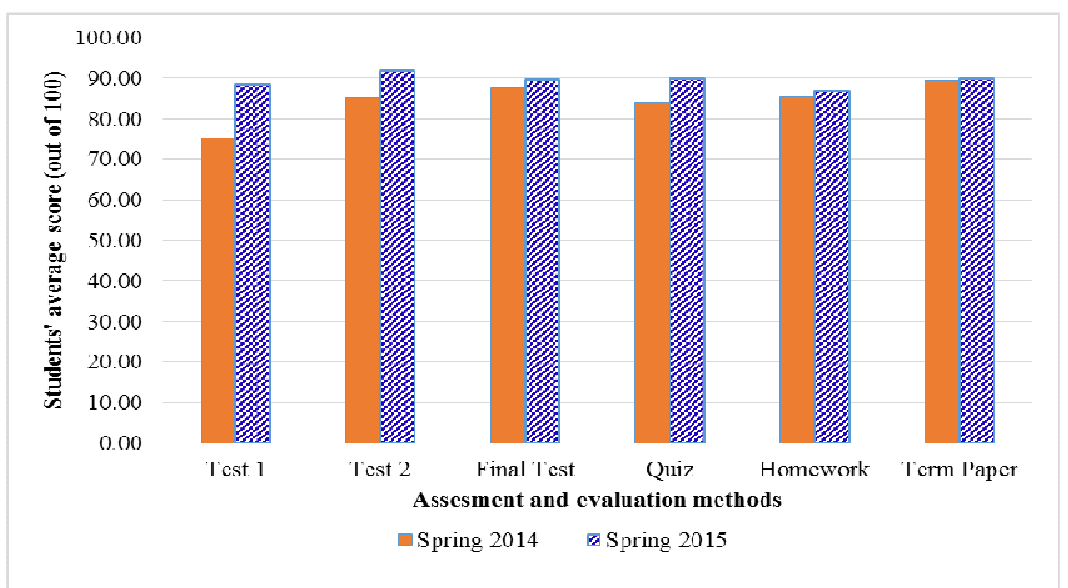

Figure 5. Students' average score in different assessment and evaluation methods in two different semesters. 
We then plotted the average grades for different evaluation methods for the given course for spring 2014 and spring 2015. We observed that students got lower average grades in spring 2014 than that in spring 2015. This happened as the instructor implemented the feedback approach more effectively and emphasized the importance of studying the lecture material after each class at least for 15 minutes. We also observed that there was no significant difference in average score for term paper as there was no direct impact of feedback process.

\subsection{Students Evaluation Conducted by the Department}

All data presented in this section are based on the student evaluation conducted independently for each course in a given semester by the Department of Electrical Engineering at GSU on behalf of the instructor. These scores were provided to the instructor by the department in the following semester (e.g. fall 2014 student evaluation reports were reported to the instructor in spring 2015) in order not to have any effect on student grading.

We then plotted the student evaluation score for the instructor for different courses as shown in Figure 6. We observed that the instructor's ratings are 4.5 or higher (out of 5) except fall 2013. It is important to point out that high rating is not only because of feedback approach but also because of the instructor's teaching skills and philosophy, integration of other technologies in the class, making learning process fun and enjoyable.

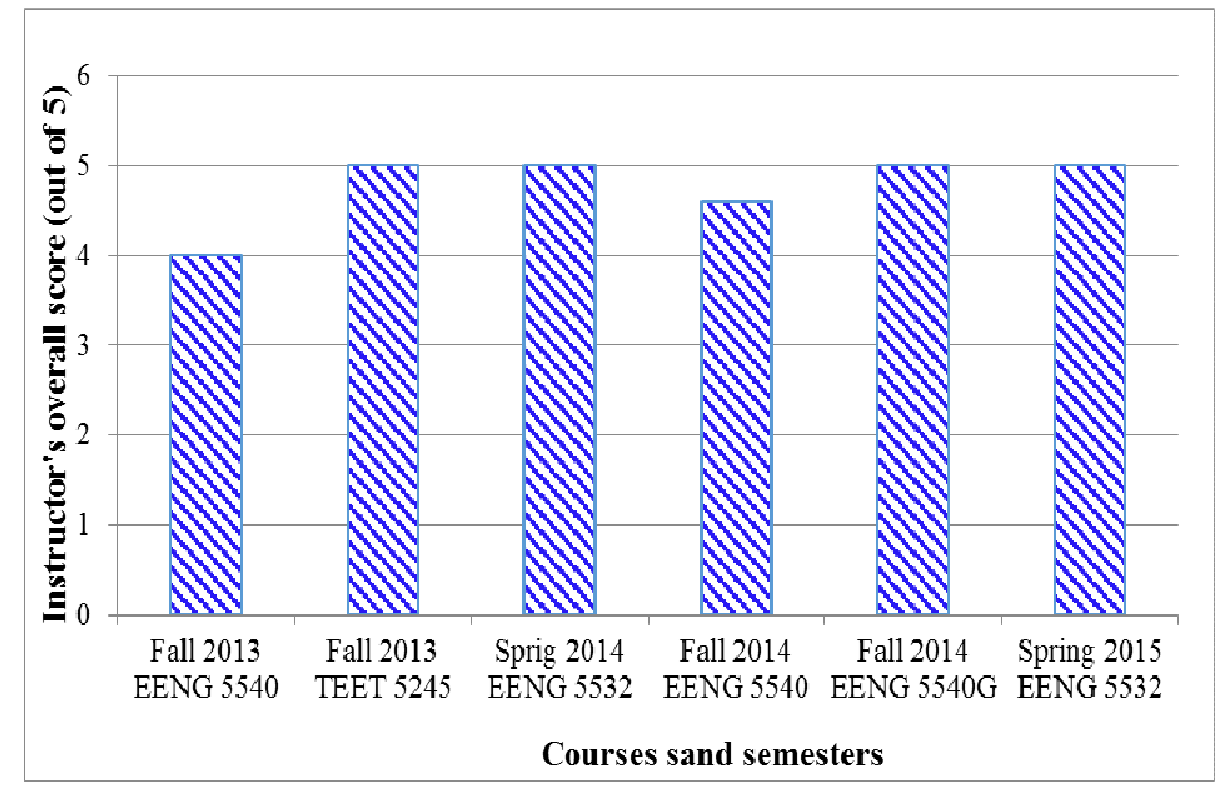

Figure 6. Student response to "Overall, how would you rate this instructor?" out of $\mathbf{5}$ for difference courses.

Next, we plotted the score for the Students' Interest Level before and after taking the course as shown in Figure 7. We observed that student interest level significantly improved after taking the course in all courses, as expected. This is because of the instructor's extra effort to make sure that students understood the fundamental concept through analogy, example, demonstrations, animations, PowerPoints, challenging homework assignment, quizzes, exams, etc. 
International Journal on Integrating Technology in Education (IJITE) Vol.4,No.3,September 2015

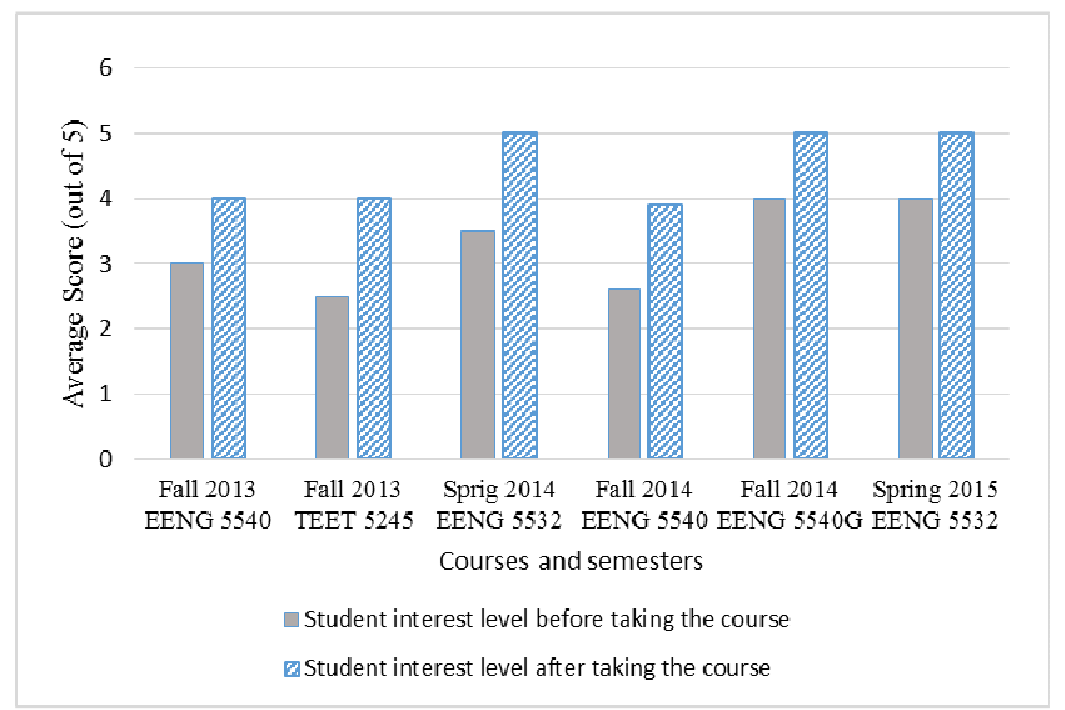

Figure 7 Student Interest Level Before and After Taking the Course (out of 5 band score).

Finally, we plotted the average score for student evaluation for a given course and content (out of 5 band score) for different courses and semesters as shown in Figure 8. The average score for each item (shown in legend of Figure 8) is higher than 4.5 (out of 5) accept that for fall 2013 EENG 5540.

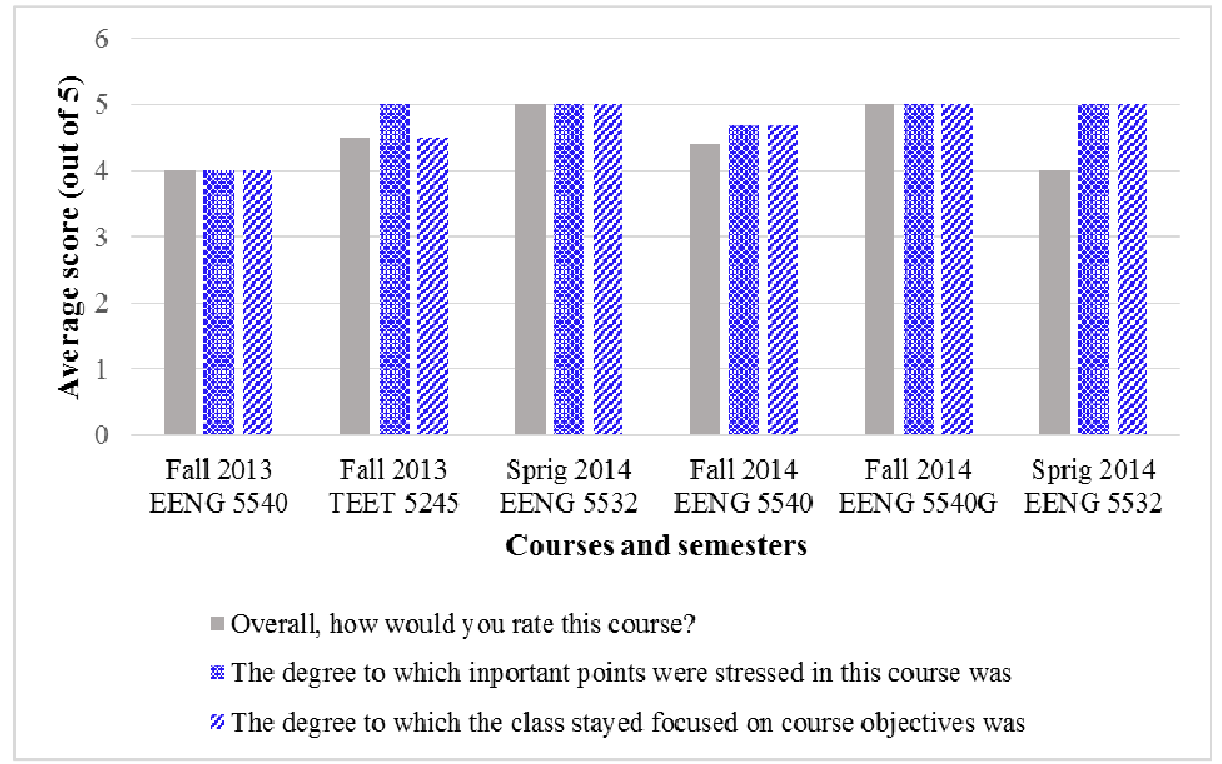

Figure 8 Student evaluation for a given course and content (out of 5 band score) for different courses and semesters.

We conclude this section by noting down that we observed similar results for other instructors who followed the similar style and the proposed approach. Thus we omitted those results in this paper. 
International Journal on Integrating Technology in Education (IJITE) Vol.4,No.3,September 2015

\section{CONCLUSION}

In this paper, we have presented a proactive anonymous feedback based adaptive teaching for enhancing student learning for engineering courses. In conventional university teaching, there are no immediate anonymous feedback mechanisms for each topic to notify the instructor about topics which are not clear to students. There are advantages that enhance students' learning experience by using a proactive anonymous feedback approach in teaching, learning and assessment. Furthermore, anonymous online based feedback mechanism provides faster feedback than conventional mechanism (where students wait until the first exam or so). Immediate feedback for each topic discussed in the class streamlines the process of reporting and the provision of active studying habit for students. The study shows that students get better grade and the instructors get better student evaluation score since the anonymous feedback provides a mechanism for students to ask questions anonymously and the instructors get an opportunity to answer the questions or concerns in a timely manner.

\section{ACKNOWLEDGEMENTS}

The authors would like to thank the students who participated in the feedback process for different courses and process of collecting data. Authors would also like to thank the anonymous reviewers who provided valuable feedback to improve the quality of the paper.

\section{REFERENCES}

[1] Michael F Graves, Connie Juel and Bonnie B. Graves, "Teaching Reading in the 21st Century," Order Processing, Allyn and Bacon, Des Moines, IA 50336-1071, 1998.

[2] Diana F. Wood, "Problem Based Learning," BMJ 326.7384, pp. 328-330, 2003

[3] Michael Prince, "Does active learning work? A review of the research," Journal of Engineering Education, Vol. 93, pp. 223-232, 2004

[4] John Bourne, Dale Harris and Frank Mayadas, "Online Engineering Education: Learning anywhere, anytime,” Journal of Engineering Education, Vol. 94, No. 1, pp. 131-146, 2005.

[5] Gongjun Yan, Danda B. Rawat, Hui Shi and Awny Alnusairl, "Developing and Applying Smartphone Apps in Online Courses," Journal of Information Systems Education, Vol. 25, No. 2, pp. 1-14, 2014.

[6] L iz. Willis and Alan Webb, "Enhancing feedback for engineering students," Higher Education Academy Engineering Subject Centre, Loughborough University, 2010.

[7] Chenicheri Sid Nair, Arun Patil, and Patricie Mertova, "Enhancing Learning and Teaching through Student Feedback in Engineering," Elsevier, 2012.

[8] Richard M. Felder, et al., "The future of engineering education II. Teaching methods that work," Chemical Engineering Education, Vol. 34, No. 1, pp. 26-39, 2000 